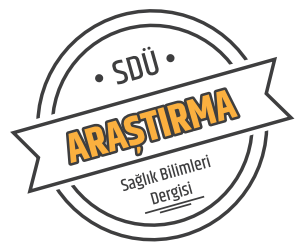

Sdü Sağlık Bilimleri Enstitüsü Dergisi / Cilt 7 Sayı 3 / 2016

\title{
Feldspatik Dental Seramiklerde Doz Hızı Ölçümleri
}

\section{Dose Rate Measurements For Feldspathic Dental Ceramics}

\begin{abstract}
Işın Kürkçüoğlu', Süleyman Hakan Tuna1, Fatih Tozun², Mehmet Ertan Kürkçüoğlu³
${ }^{1}$ Süleyman Demirel Üniversitesi, Diş Hekimliği Fakültesi, Protetik Diş Tedavisi Anabilim Dalı, Isparta, Türkiye.

${ }^{2}$ Süleyman Demirel Üniversitesi, Fen-Edebiyat Fakültesi, Fizik Bölümü, Isparta, Türkiye. ${ }^{3}$ Süleyman Demirel Üniversitesi, Fen-Edebiyat Fakültesi, Fizik Bölümü, Nükleer Fizik Anabilim Dalı, Isparta, Türkiye.
\end{abstract}

\section{Özet}

Amaç: $\mathrm{Bu}$ çalışmanın amacı, diş hekimliğinde protetik restorasyonların üretiminde kullanılan 8 farklı markaya ait feldspatik yapıdaki 42 seramik tozu örneğinin $(n=2)$ sahip olduğu doz hızı düzeylerini saptamaktır.

Materyal-Metot: Doz hızı ölçümleri, 10'ar gramlık örnekler için $\alpha, \beta$ ve $\gamma$ radyasyonlarını algılayabilen yass1-pencereli seyyar bir Geiger-Müller dedektörünün yer aldığı bir deneysel düzenekle gerçekleştirilmiştir. Her bir örnek için 9600 ölçüm verisi alınarak numunelerin sahip olduğu net doz hızlarına ait ortalamalar; alfa, beta, gama ve toplam doz hızı olarak belirlenmiştir.

Bulgular: Bu çalışma sonucunda, örneklere ait net toplam doz hızlarının 1,32 mSv/yıl ile 2,17 mSv/yıl arasında değiştiği ve ortalamanın 1,76 mSv/yıl düzeyinde olduğu tespit edilmiştir. $\beta$ doz hızının bu ortalamaya katkısı 1,41 mSv/yıl değeriyle ilk sirada yer alırken, $\gamma$ doz hızı katkısının $0,21 \mathrm{mSv} / \mathrm{y} 1 \mathrm{l}$ ve $\alpha$ doz hızı katkısının da $0,14 \mathrm{mSv} / \mathrm{y}$ l olduğu bulunmuştur.

Anahtar Kelimeler: Dental Seramikler, Doğal Radyoaktivite, Doz Hizı.

\section{Giriş}

Radyoaktivite, nükleonlardan oluşan atom çekirdeğinin kararlı ve kararsız durumlarıyla ilişkili bir kavramdır. Radyoaktif çekirdekler (radyonükleidler), bünyelerindeki fazla enerjiyi çeşitli mekanizmalarla kaybederek, yani radyasyon yayınlayarak kararlı hale geçme eğilimi gösterirler (1). Canlılar yaşamları boyunca, gerek doğal gerekse yapay radyasyon kaynakları nedeniyle kaçınılmaz bir biçimde iyonlaştırıcı tipteki radyasyona (alfa $(\alpha)$, beta $(\beta)$ ve gama $(\gamma)$ radyasyonlarına) maruz kalırlar. Bir yılda kişi başına alınan ortalama radyasyon seviyesinin $2,8 \mathrm{mSv}$ civarında olduğu ve bunun yaklaşık \%85'ini doğal kaynakların oluşturduğu bildirilmektedir (2). Doğada hiçbir etkiye maruz kalmadan kendiliğinden bozunan doğal radyoaktif maddelerin başlıca kaynakları evren, yerküre ve güneştir. Topraktaki doğal radyasyona

\begin{abstract}
Objective: The aim of this study was to determine dose rate levels of 42 feldspathic dental ceramic powder samples $(n=2)$ used for the production of prosthetic restorations in dentistry that were obtained from eight different manufacturers. Materials-Method: After preparing 10 grams of powder specimens from each dental ceramic sample, the dose rate measurements were performed by using an experimental setup with a portable, flat-window Geiger-Muller detector, which is able to detect $\alpha, \beta$ and $\gamma$ radiations. Ninety six hundreds measurement data were recorded for each specimen. Net dose rate averages were determined in terms of alpha, beta, gamma and total dose rates.
\end{abstract}

Results: According to the dose rate measurements, it was found out that, the net total dose rate values of the samples were varied from $1.32 \mathrm{mSv} / \mathrm{y}$ to $2.17 \mathrm{mSv} / \mathrm{y}$ with an average of $1.76 \mathrm{mSv} / \mathrm{y}$. The contribution of the $\beta$ dose rate to the total dose rate average was the greatest with $1.41 \mathrm{mSv} / \mathrm{y}$. This was followed by the $\gamma$ and $\alpha$ dose rates of $0.21 \mathrm{mSv} / \mathrm{y}$ and 0.14 $\mathrm{mSv} / \mathrm{y}$ respectively.

Key Words: Dental Ceramics, Natural Radioactivity, Dose Rate.

neden olan temel radyoaktif elementler; Uranyum-238, Uranyum-235 ve Toryum-232 serilerinin bozunma ürünleri ve Potasyum-40 olup yer kürede bulunan bu doğal kaynaklar arasında Uranyum-238 ve bozunma ürünleri en büyük paya sahiptir. Doğal radyonükleidlerden yayınlanan iyonize radyasyon, doğrudan dış 1şınlanma yoluyla veya solunum ve sindirim mekanizmalarıyla vücut içine alındığında iç 1şınlanma yoluyla risk oluşturabilir. Dolayısıyla, yaşadığımız bölgenin radyasyon düzeyinin bilinmesi, tükettiğimiz yiyecek ve içecek maddeleriyle, günlük yaşamda kullandığımız materyallerin içerdiği radyoaktivitenin ölçülmesi halk sağlığı bakımından önem taşıyan bir konudur.

Biyolojik yapılara aktarılan radyasyon enerjisi, canlı dokular ile etkileştiğinde, dokulara hasar verme potansiyeline sahiptir. Meydana gelen hasar, radyasyonun türüne, enerjisine ve etki süresine göre; onarılabilen veya onarılamayan biçimde 
olabilmektedir. İyonize radyasyon ile karşılaşan hücrede oluşacak senaryolar; nesilden nesile aktarılan kalıtsal etkiler, kanser gibi daha sonra meydana gelen kusurlar veya hücrenin ölümü şeklinde gerçekleşebilmektedir (3).

Dayanıklı kimyasal yapıları ve translusent (yarı-şeffaf) özelliğinden dolayı estetik amaçlar için en doğal görünümlü restoratif materyaller olarak kabul edilen ve diş hekimliğinde yaygın olarak kullanılan dental seramikler, yapılarında doğal radyonükleidler barındırabilirler. Farklı oranlarda olmakla birlikte tüm seramiklerde temel yap1 feldspar, kuartz ve kaolinden oluşur (4). Potasyum alüminyum silikat (K2OA12O6SiO2) ve albit'in (Na2OA12O6SiO2) karışımı olan feldspar doğada saf olarak bulunmaz. Potas (K2O) ve soda (Na2O) oranları da değişkenlik gösterebilmektedir (5). Silika yapısında olan kuartz ( $\mathrm{SiO} 2)$, firınlama esnasinda porselen yapıya doldurucu ve güçlendirici görevi yapar. Bir alüminyum hidrat silikat (A12O32SiO22H2O) olan kaolin opaktır ve dental porselenlerde oldukça az miktarda kullanılır veya hiç kullanılmaz (4). Bu üç temel bileşenin dışında seramiklere; çeşitli renklendirici pigmentler, opaklaştırıcı veya floresans özelliğini geliştiren çeşitli ajanlar, akışkanlar, cam modifiye ediciler ve ara oksitler eklenebilmektedir. Dental seramikler için farklı kriterlere göre çeşitli sınıflandırmalar yapılabilir. Dental seramiklerin kullanım alanlarına, işlem tekniğine, kimyasalyapılarına, firınlamasıcaklıklarınaya damikroyapısal özelliklerine göre sınıflandırılması daha yaygındır (4, 6-8).

Protetik diş tedavisinde amaç en doğal görünümlü restoratif materyali kullanmaktır. Seramik materyaller de daha doğal bir görünüm verebilmek ve diş yapılarının opak, floresans ve translusent özelliklerini taklit edebilmek amacıyla çeşitli malzemelerin ilavesiyle modifiye edilmişlerdir (4). Dental seramiklerde, doğal dişlere benzer bir floresanslık özelliğinin, Uranyum bileşiklerinin porselen tozlarına katılmasıyla elde edilebileceği fikri, ilk defa, Dietz tarafından 1942 yilında Amerika Birleşik Devletleri'nde ortaya konmuştur (9). Bu şekilde doğal dişe daha çok benzeyen görünüm kısa sürede üreticilerin dikkatini çekmiş ve Uranyum bileşiklerinin dental porselenlerekatılmasıfikri,ticariolarakkabulgörmüştür.Ancak Uranyum'un bütün tuzları ve izotopları radyoaktif olduğu için dental porselenlere katılan Uranyum bileşiklerinin neden olabileceği biyolojik etkiler tartışma konusu olmuştur. (10).

Protetik restorasyonlarda kullanılan dental seramiklerin içerdiği radyonükleidlerin neler olduğu ve miktarlarının belirlenmesi, bu materyalleri kullananların maruz kalacağ1 dozların saptanabilmesi açısından önemlidir. Bu konudaki literatürler incelendiğinde, protezleri kullanan kişiler hakkında radyasyon kaynaklı bir sağlık sorununu bildiren herhangi bir rapor bulunmamaktadır. Ancak, dental seramiklere bağlı olarak kişilerin maruz kalabilecekleri radyasyon dozlarını inceleyen sınırlı sayıda çalışma mevcuttur $(11,12)$. Radyasyonun canlı yapılar ile etkileşiminden yola çıkarak alfa, beta ve gama radyasyonlarının her birinin farklı boyutta etkilerinin olacağı tartışılabilir. Seramik restorasyonun bulunduğu ağız içerisinde, diş çevresindeki epitel dokunun sürekli olarak alfa radyasyonuna maruz kalacağı ve oral veya bazal mukozanın da beta radyasyonundan etkileneceği bazı çalışmalarda vurgulanmaktadır (10-12). Beta radyasyonunun dokulara penetrasyonunun alfa radyasyonuna göre daha fazla olması nedeniyle insan sağlığı açısından etkisinin oldukça önemli olduğu düşünülmektedir (13). Beta ve gama yayınlayıcısı olan ve feldspatik yapıdaki seramiklerde oldukça yüksek miktarda bulunan Potasyum-40 radyoçekirdeğine de ayrıca dikkat çekilmektedir (12). 1979 yılında Amerikan Diş Hekimleri Birliği (ADA), dental porselen ve porselen dişlerdeki Uranyum içeriğinin standart hale getirilmesi için 52 nolu şartnameyi hazırlamıştır (14). Bu düzenlemeyle birlikte porselen dişlerde kullanılan Uranyum miktarında azaltma yapılmış, ağırlık olarak \%0,03 seviyesi $(\sim 3,7 \mathrm{~Bq} / \mathrm{g})$ müsaade edilebilecek miktar olarak belirlenmiştir (14). Dental porselen üreticileri bu standartlara bağlı kalarak Uranyum ile yer değiştirebilecek alternatif madde arayışına girmişlerdir. 1980'lerin başında ABD'deki büyük üretici firmalardan biri, dental seramiklerde Uranyum'u kullanmayı bırakmıştır. Ancak dental seramiklerin floresans davranışlarının doğal dişlere benzetilmesi sorunu kısa sürede çözülememiştir. 1990'lı yıllarda ADA, 69 nolu şartnamesi ile üreticilere, seramiklere radyoaktiviteyi arttıracak bir floresan ajanı eklenmediğini garanti eden bir belge sunma zorunluluğu getirmiştir (15). Uluslararası Standartlar Örgütü (ISO) tarafindan yapılan en son düzenlenmeye (ISO 6728) göre, günümüzde porselen tozu üretiminde dental seramiklerin 238U aktivite konsantrasyonu bakımından 1Bq/gr değerini aşmaması gerektiği bildirilmektedir (16). Ayrıca, Avrupa Komisyonu (EC) tarafından dental seramikler için özel bir limit belirtilmemekle birlikte, katı malzemelerin yer aldığı tüketici ürünlerinin içerebileceği doğal radyonükleidler hakkında muafiyet ve tavsiye düzeyleri tanımlanmıştır $(40 \mathrm{~K}$ için $10 \mathrm{~Bq} / \mathrm{g}$, $238 \mathrm{U}$ ve $232 \mathrm{Th}$ için $1 \mathrm{~Bq} / \mathrm{g}$ ) (17). Türkiye'deki uygulamalar için iyonlaştırıcı radyasyon ile ilgili limitlerin belirlenmesi ve gerekli denetimlerin yapılması konularında yaptırım yetkisine sahip olan otorite Türkiye Atom Enerjisi Kurumu'dur (TAEK'dir). TAEK'in radyasyon güvenliği yönetmeliğinde radyasyonla çalışanlar ve halk için belirlediği limitler (18) mevcut olmakla birlikte, diş hekimliğinde kullanılan dental seramikleri de kapsayan dental ürünler hakkında, mevzuatlarında herhangi bir düzenleme bulunmamaktadır. Ülkemizdeki diş hekimliği uygulamalarında, en çok kullanılan feldspatik yapidaki dental seramiklere ait doz hızlarının incelendiği ilk ulusal araştırma olma niteliği taşıyan bu çalışmanın izleyen bölümünde kullanılan yöntem tanıtılmaktadır. Daha sonra elde edilen net ölçüm sonuçları sunulmakta, $\alpha, \beta$ ve $\gamma$ doz hızlarının toplam doz hızına katkıları tartışılarak bulgularlar karşılaştırmalı olarak değerlendirilmektedir.

\section{Materyal-Metot}

Radyasyon ölçümlerinde kullanılan dedektörlerin çalışma prensipleri birbirlerine benzer özellikler gösterir. Genel olarak, incelenecek numuneye ait radyasyon, dedektör bölmesine girerek buradaki atomlarla etkileşir ve enerjisinin bir kısmını veya tamamını kaybederek iyonizasyona (elektron salınımına) neden olur. Toplanan bu elektronlar, bir elektronik devre tarafından akım atması veya potansiyel farkı şeklinde ölçülerek analiz edilir. Farklı tipteki dedektörlerle ölçülebilen $\alpha, \beta$ ve 
$\gamma$ radyasyonlarının genel özellikleri şu şekilde özetlenebilir: Alfa radyasyonu: İki proton ve iki nötrondan oluşan Helyum çekirdeği $\left({ }_{2}^{4} \mathrm{He}\right)$ olup $\alpha$ sembolü ile gösterilir. İyonlaştırıcı olan alfa radyasyonu, nispeten ağır kütlesi nedeniyle havada çok çabuk etkileşime girerek kisa bir mesafe ilerler (19). Alfa radyasyonunun madde içerisindeki penetrasyonu düşüktür, doğal kaynaklı alfa radyasyonu ince bir kağıt veya vücut derisi tarafından tamamen durdurulabilir. Ürünleri arasında $\alpha$ parçacığı bulunan radyoaktif maddeler solunum ve sindirim yoluyla vücuda alınırsa akciğer ve mide dokularını yüksek radyasyon dozuna maruz bırakabilirler. Toksik etkisi nedeniyle nükleer tıpta kullanılan bir parçacık değildir. Doğal radyoaktif kaynaklardan yayınlanan alfa parçacıkları 2-10 MeV arasında değişen enerjilere sahiptir.

Beta radyasyonu: Kararsız bir çekirdek, sahip olduğu fazla proton veya nötronundan bir protonu nötrona veya bir nötronu protona dönüştürerek daha kararlı hale gelme eğilimindedir. $\mathrm{Bu}$ durum 3 farklı mekanizmayla meydana gelebilir. Her üç işlemde de elektrik yükünün korunabilmesi için diğer bir yüklü parçacığın bu reaksiyonlarda yer alması gerekir. Bu üç nükleer olay beta bozunması kapsamında açıklanır (19). Önceleri beta parçacığı olarak nitelenen bu yüklü parçacığın elektrona özdeş olduğu daha sonra anlaşılmıştır. Beta parçacığı, alfa parçacığına göre daha hafif olduğundan iyonizasyon yeteneği daha düşüktür. Bununla birlikte, alfa parçacıklarına göre daha fazla girişken olan $\beta$ radyasyonu, doku veya malzemeler içine daha fazla nüfuz edebilmektedir. Doğal kaynaklı beta parçacıkları cildin üst tabakasından öteye ilerleyemeseler de yüksek enerjili beta radyasyonuna aşırı derecede maruz kalındığında cilt yanıkları görülebilmektedir. Genel olarak, beta yayınlayıcıların sadece solunum ya da sindirim yoluyla vücuda alındığında tehlikeli olacağı bildirilmektedir (2).

Gama radyasyonu: Çekirdek içinde gerçekleşen nötron, alfa veya beta bozunmaları ardından ortaya çıkan kararsız çekirdek, uyarılmış enerji seviyesinde kalabilir ve ikinci bir bozunma ile (bir foton yayınlayarak) kararsız durumdan kararlı duruma geçebilir. Bu geçiş sırasında yayınlanan fotonlar, gama 1şınlarıdır. Doğal bozunma mekanizmaları sonucunda ortaya çıkan gama radyasyonu 0,1 ile $10 \mathrm{MeV}$ arasında enerjilere sahip olabilir (20). Gama 1şınlarının sahip olduğu enerjilerine bağlı olarak madde ile gerçekleştirebileceği çeşitli etkileşmeler mevcuttur (19). Yüksek penetrasyona sahip gama 1şınları doğrudan vücut içerisine girerek enerjisini iç organlara aktarabilir. Gama radyasyonuna maruz kalmak canlıları olumsuz şekilde etkileyebilir. Diğer taraftan tıbbi teşhis ve tedavide de kullanım alanına sahip olan gama 1şınları, kurşun ve baritli beton gibi yüksek yoğunluklu malzemelerle zırhlanmaktadır. Birkaç santimetre kalınlığındaki kurşundan geçebilecek enerjiye sahip doğal kaynaklı $\gamma$-1şınları, bulundukları ortamı dolaylı yoldan iyonize ederler (1). Yerkürede mevcut olan başlıca doğal radyoaktif kaynaklar incelendiğinde; ${ }^{222} \mathrm{Rn}$ ve ${ }^{220} \mathrm{Rn}$ 'nin alfa, ${ }^{40} \mathrm{~K},{ }^{87} \mathrm{Rb},{ }^{90} \mathrm{Sr},{ }^{90} \mathrm{Y},{ }^{137} \mathrm{Cs},{ }^{214} \mathrm{~Pb}$ ve ${ }^{214} \mathrm{Bi}$ ' un beta, ${ }^{40} \mathrm{~K},{ }^{238} \mathrm{U},{ }^{232} \mathrm{Th}$ ve 226Ra'nın gama yayınlayıcıları olduğu görülmektedir.

\section{Doz Hızı Ölçümlerinde Kullanılan GM Dedektörü}

GM (Geiger-Müller) dedektörü 1928 yılında Geiger ve Müller tarafından bulunan en eski radyasyon ölçüm dedektörüdür. $\mathrm{Bu}$ dedektör, bir malzemenin veya bir numunenin bir saniyede meydana getirdiği radyoaktif bozunmaları saymak için kullanılmaktadır. Çalışma kapsamında gerçekleştirilen sayım hızı ölçümleri için RadEye B20ER (Thermo, Almanya) cihazı kullanılmıştır. $\mathrm{Bu}$ cihaz $\alpha, \beta$ ve $\gamma$ radyasyonlarını algılayabilen, yassı pencereli, 300 gr ağırlığında, seyyar bir GM sayıcısıdır (Şekil 1). Farklı tipteki radyasyonları ayırt edebilmek için cihaz ile birlikte özel hazırlanmış filtreler kullanılmaktadır (Şekil 2). Cihaz, filtresiz olarak kullanıldığında 6-10 $\mathrm{keV}$ aralığındaki foton enerjilerini ölçmektedir. Gama filtresi kullanıldığında, $17-1300 \mathrm{keV}$ aralığında gama doz hızı ölçümleri yapılabilmektedir.Ayrıca, ortamdaki alfa parçacıklarının dedektörde sayılmasını engellemek için bir alfa bloklayıcı filtre opsiyonu da mevcuttur.

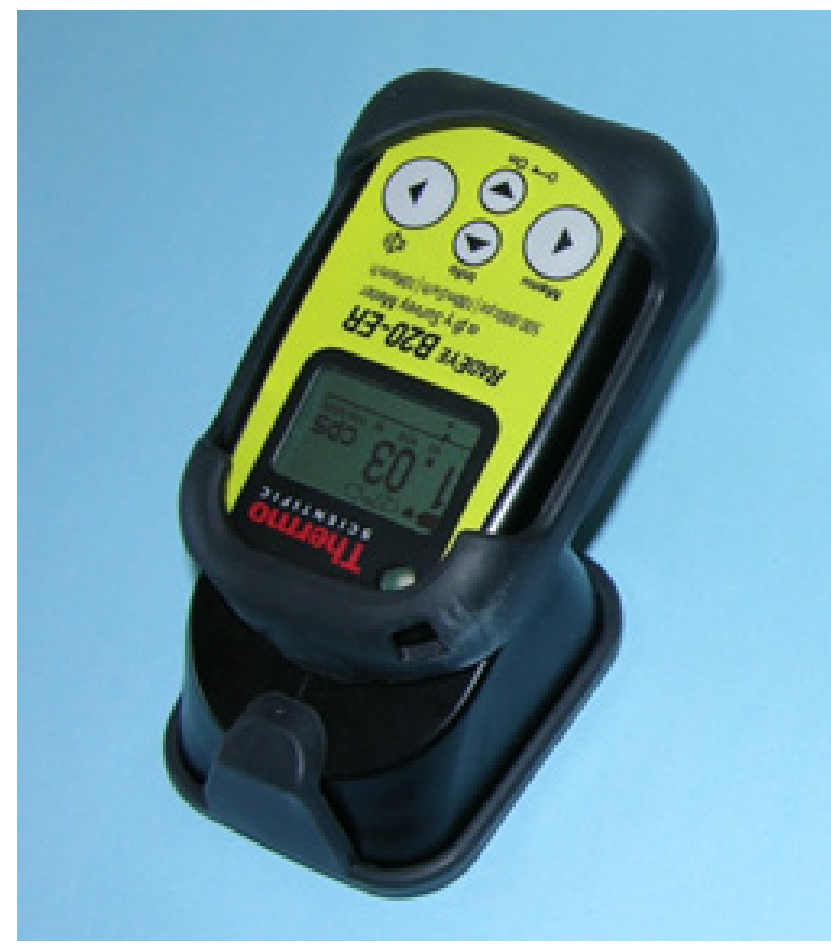

Şekil 1. Ölçümlerde kullanılan GM dedektörü.

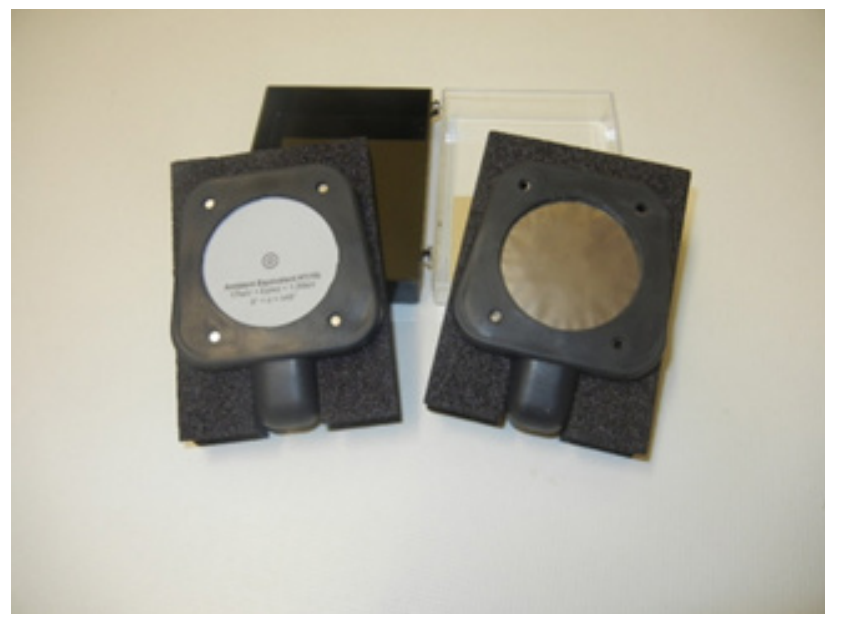

Şekil 2. GM dedektörünün penceresiyle uyumlu $H^{*}(10)$ gama filtresi (solda) ve alfa bloklayıcı filtre (sağda). 
Katı veya sıvı numunelere ait doz hızı ölçümleri yapmak için cihaz ile birlikte özel olarak tasarlanmış bir numune tutucusu (numune değiştiricisi) kullanılmaktadır (Şekil 3).

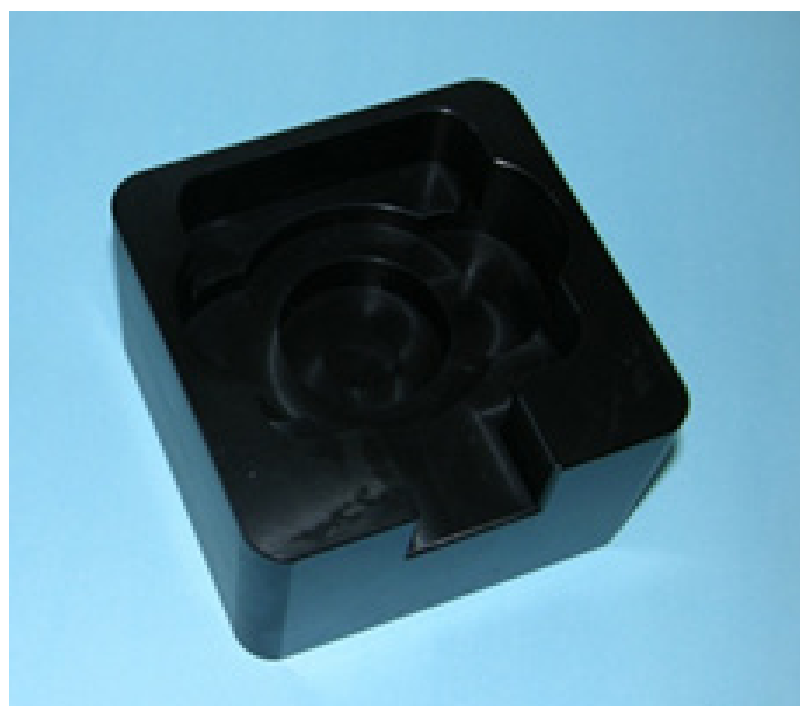

Şekil 3. Doz hızı ölçümlerinde kullanılan örnek tutucu aparat.

Doz hızı ölçümleri genellikle sayım hızı cinsinden yapılmaktadır (cps: saniye başına sayım). Ayrıca doz hızı, (Cs137 test protokolünde, kalibrasyon çarpanının tersi alınarak) sayım/saniye biriminden $\mu \mathrm{Sv} / \mathrm{h}$ birimine çevrilebilir;

$$
1 \mathrm{cps}=0,1922 \mu \mathrm{Sv} / \mathrm{h} \text {-Denklem }(
$$

RadEye B20-ER ile brüt (gross) veya net sayım ölçümleri yapılabilir. Brüt sayım hızı ölçümlerinin, net sayım hızı ölçümleri olarak ifade edilebilmesi için ortamın doğal fon (background) radyasyonu bilinmelidir. Bunun için cihaz içerisinde fon radyasyonunu belirleyebileceğimiz bir menü mevcuttur. Fon radyasyonunun belirlenmesi için cihazla ön ölçümler yapılarak bu değer cihaza fon değeri olarak kaydedilir. Bu sayede, numunelerdeki anlık net sayım hızları otomatik olarak cihazda görüntülenebilir. Ölçüm sonunda cihazla alınan veriler, cihazın hafızasına kaydedilir. Ölçülen verilerin, cihaza ait "radeye.exe" yazılımında işlenebilmesi için bilgisayara aktarılması gerekmektedir. $\mathrm{Bu}$ işlem RS232 bağlantılı bir kızıl ötesi aktarım elemanıyla sağlanır. Cihazının radyasyona verdiği tepki, radyasyon kaynağına olan uzaklığa ve açısal konuma göre değişmektedir. Cihaz için değişik enerji aralıklarına göre yapılan çalışmada, $H^{*}(10)$ gama filtresi için 100 derecelik, H'(0,07) alfa filtresi için ise yaklaşık 90 derecelik bir açı içerisindeki radyasyonun başarılı bir şekilde algılanabileceği bildirilmektedir (21).

\section{Ölçüm Düzeneği}

Çalışmamızda 8 farklı üreticiye ait 42 farklı feldspatik dental seramik tozu kullanılmış (Şekil 4) ve ölçümler için hassas terazi yardımıyla 10'ar gramlık 2'şer örnek hazırlanmıştır. Hazırlanan örnekler, fon radyasyonundan etkilenmemesi için ölçüm süreci öncesinde kapalı kaplarda muhafaza edilmiş ve örnekler üzerinde herhangi bir kimyasal işlem yapılmamıştır. İncelenen örnekler Tablo 1'de gösterilmektedir. 10 gramlık örnek miktarı, ölçüm düzeneğindeki dedektör penceresi boyutu, numune tutucusunun ölçüleri ve burada

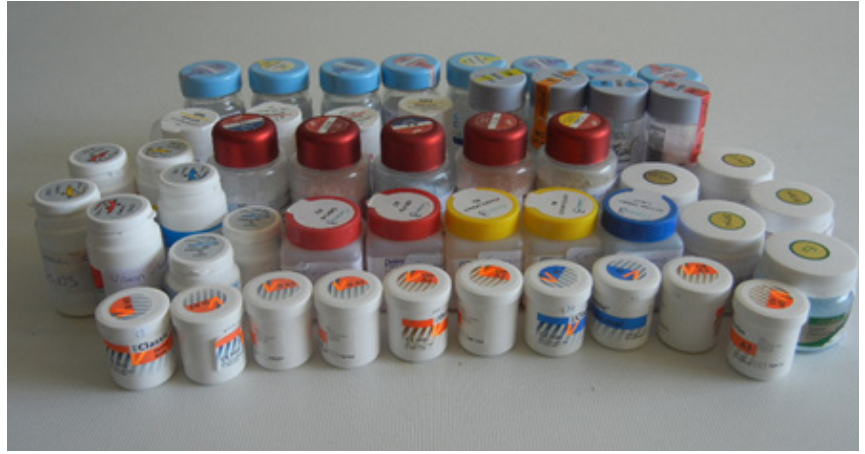

Şekil 4. Ölçümlerde kullanılan feldspatik dental seramik örnekleri.

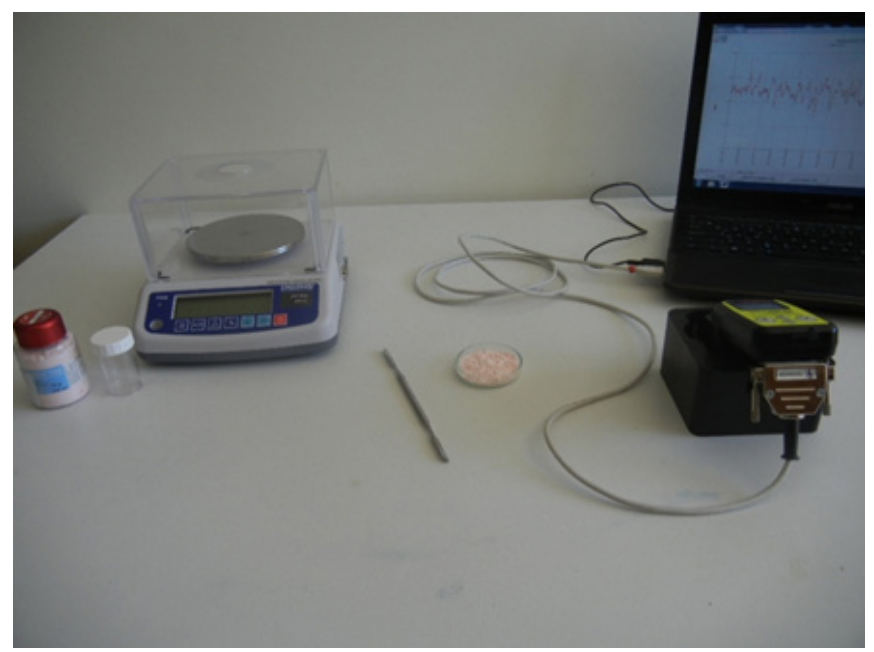

Şekil 5. Doz hızı ölçümleri için kurulan deneysel düzenek.

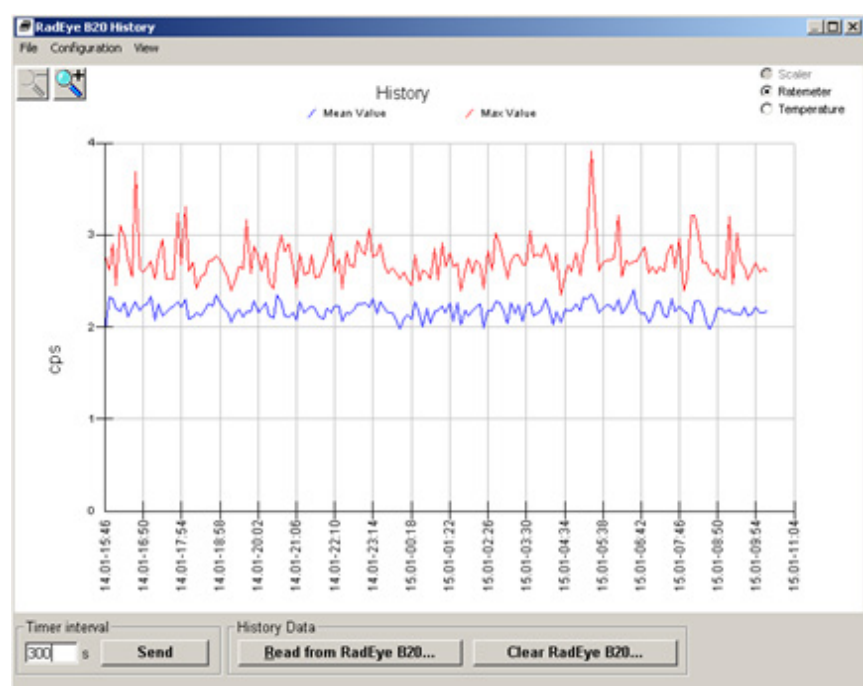

Şekil 6. RadEye cihazıyla bir örnek için alınan ön ölçümlere ait doz hızı verilerinin zamana bağlı değişimi (Dedektör ratemeter modunda, herhangi bir filtre kullanılmaksızın çalıştırılmış, doz hızı ölçümlerine ait grafikler radeye.exe programında oluşturulmuştur. Grafiğin y-ekseni sayım/saniye cinsinden doz hızını, x-ekseni ise alınan ölçümlerin tarih ve zamanını göstermektedir. Grafikteki mavi çizgi ortalama sayım hızı değerlerini, kırmızı çizgi ise periyodik okuma aralığı içinde saptanan maksimum sayım hızı değerlerini göstermektedir). 
kullanılabilecek petri kabı boyutları göz önüne alınarak belirlenmiştir.

Doz hızı ölçümlerinde kullanılan deneysel düzenek Şekil 5'te gösterilmektedir. Petri kabı içerisine konulan 10 gramlık bir örnek, numune tutucusuna yerleştirilmiş ve daha sonra RadEye B20-ER dedektörü (ölçülecek radyasyon türüne göre dedektör ile birlikte ilgili filtre kullanılarak veya toplam doz hızı ölçümü için filtre kullanılmaksızın), numune tutucusu üzerindeki yuvasına oturtularak sabitlenmiştir. Dedektör, sayım hızı (cps) biriminde ve gerçek okumaların anlık olarak cihazın ekranında gösterildiği modda ölçüm alacak şekilde çalıştırılmıştır. Dedektörün hafızasına kayıt ettiği veriler, cihaza özel olarak üretilmiş kızıl ötesi bağlantı aparatı ile bir bilgisayara aktarılmış ve elektronik ortamda "radeye.exe" yazılım programı kullanılarak işlenmiştir (Şekil 6).

RadEye B20-ER dedektörüyle gerçekleştirilen 4800 saniyelik bir ölçümün sonunda, dedektörün hafizasında tutabildiği maksimum kapasite olan 1600 veri alınarak kayıt edilmiştir. Dedektör filtresiz olarak, alfa bloklayıcı filtre ile birlikte ve daha sonra da gama filtresi kullanılarak çalıştırılmış ve ilgili doz hızları için örnek başına üç ayrı veri grubu oluşturulmuştur. Radyoaktivitenin rastgele bir proses olması nedeniyle radyoaktif element içeren bir malzemenin yayınladığı radyasyon miktarı zamana göre farklılıklar gösterebilmektedir. Bu durum göz önüne alınarak her bir dental seramik tozu numunesi için hazırlanan iki örneğin ölçümleri farklı tarihlerde gerçekleştirilmiştir. Böylelikle ölçümleri tamamlanan 84 örnek için 252 veri grubu elde edilmiştir. Bir örneğe ait herhangi bir brüt sayım hızı değerinin belirlenebilmesi için bu ölçümde alınan 1600 verinin ortalaması kullanılmıştır. Ayrıca, elde edilen brüt ölçüm sonuçları kullanılarak numunelerin sahip olduğu net sayım hızı değerlerinin belirlenmesi için laboratuardaki fon radyasyonu seviyesinin bilinmesi gerektiğinden ölçüm dönemleri öncesinde boş ölçümler alınarak fon düzeyleri tespit edilmiştir.

\section{Bulgular}

Çalışma kapsamında incelenen 84 örneğe ait brüt sayım hızı ortalamaları, Kasım 2013 ve Haziran 2014 tarihleri arasında yaklaşık 8 aylık bir süre boyunca gerçekleştirilen ölçümler sonucunda elde edilmiştir. Tablo 1'de listelenen 42 dental seramik numunesine ait 1 . ve 2 . ortalama brüt sayım hızı ölçümlerinin ortalamaları hesaplandıktan sonra, dönüşüm denklemi (1) kullanılarak ve fon radyasyonunun etkisi değerlendirmeye alınarak net doz hızları, mSv/yıl cinsinden belirlenmiştir. Fon radyasyonu seviyelerinin tayininde GM dedektörü ile farklı tarihlerde, filtreli ve filtresiz durumlarda 4'er ölçüm alınmış ve hesaplamalar için bu ölçümlere ait ortalamalar kullanılmıştır (Fon ölçümlerinde örneklere uygulanan sayım kriterleri baz alınmış, yani her fon seviyesi ölçümü için 4800 saniye süreyle 1600 veri alınmıştır). Böylelikle, fon seviyelerine ait sayım hızları, filtresiz durumdayken 1,22 cps, alfa bloklayic1 filtre ile 1,20 cps ve gama filtresi kullanıldığında ise 1,02 cps olarak tespit edilmiştir. Numunelere ait net doz hızı sonuçları $(\alpha, \beta, \gamma$ ve toplam doz hızları için) Tablo 2'de verilmektedir.
Tablo 1. Dental seramik örnekleri için kullanılan kodlama.

\begin{tabular}{|c|c|c|c|}
\hline Marka & Numune Kodu & $\begin{array}{c}\text { Uygulama } \\
\text { yeri }\end{array}$ & $\begin{array}{l}\text { Renk } \\
\text { Kodu }\end{array}$ \\
\hline \multirow{5}{*}{ Ceramco } & $\mathrm{C} 1$ & Dentin & $\mathrm{A} 2$ \\
\hline & $\mathrm{C} 2$ & Dentin & A3 \\
\hline & $\mathrm{C} 3$ & Opak & $\mathrm{A} 2$ \\
\hline & $\mathrm{C} 4$ & Opak & A3 \\
\hline & $\mathrm{C} 5$ & Enamel & Natural \\
\hline \multirow{5}{*}{ Noritake } & N1 & Dentin & $\mathrm{A} 2$ \\
\hline & N2 & Dentin & A3 \\
\hline & N3 & Opak & A2 \\
\hline & N4 & Opak & A3 \\
\hline & N5 & Enamel & E2 \\
\hline \multirow{5}{*}{$\begin{array}{c}\text { Degudent } \\
\text { Duceram } \\
\text { Kiss }\end{array}$} & D1 & Dentin & A2 \\
\hline & D2 & Dentin & A3 \\
\hline & D3 & Opak & A3 \\
\hline & D4 & Transparent & Clear \\
\hline & D5 & Incisal & $\mathrm{S} 2$ \\
\hline \multirow{6}{*}{$\begin{array}{l}\text { Vision } \\
\text { Classic }\end{array}$} & $\mathrm{VC} 1$ & Dentin & A2 \\
\hline & $\mathrm{VC} 2$ & Dentin & A3 \\
\hline & VC3 & Opak & A2 \\
\hline & $\mathrm{VC4}$ & Opak & A3 \\
\hline & VC5 & Enamel & $\mathrm{I}-58$ \\
\hline & VC6 & Transparent & Clear \\
\hline \multirow{5}{*}{$\begin{array}{c}\text { Ivoclar } \\
\text { Vivadent IPS }\end{array}$} & I1 & Dentin & A2 \\
\hline & $\mathrm{I} 2$ & Dentin & A3 \\
\hline & $\mathrm{I} 3$ & Opak dentin & A2 \\
\hline & $\mathrm{I} 4$ & Opak dentin & A3 \\
\hline & I5 & Transparent & Natural \\
\hline \multirow{4}{*}{ GC Inital } & G1 & Dentin & A2 \\
\hline & G2 & Opak & $\mathrm{A} 2$ \\
\hline & G3 & Opak dentin & A2 \\
\hline & G4 & Enamel & E58 \\
\hline \multirow{4}{*}{$\begin{array}{c}\text { Vita WMK } \\
\text { Master }\end{array}$} & $\mathrm{V} 1$ & Dentin & $2 \mathrm{~L} 1,5$ \\
\hline & $\mathrm{V} 2$ & Dentin & $2 \mathrm{R} 2,5$ \\
\hline & V3 & Opak & A2 \\
\hline & V4 & Opak & A3 \\
\hline \multirow{8}{*}{ Matchmaker } & M1 & Dentin & A2 \\
\hline & M2 & Dentin & A3 \\
\hline & M3 & Opak & A1 \\
\hline & M4 & Opak & A2 \\
\hline & M5 & Enamel & E8 \\
\hline & M6 & Enamel & E9 \\
\hline & M7 & Enamel & Natural \\
\hline & M8 & Enamel & Clear \\
\hline
\end{tabular}


Tablo 2. Örneklere ait net doz hızı ortalamaları (Htop net toplam doz hızı, H $\alpha$ net alfa doz hizı, $\mathrm{H} \beta$ net beta doz hızı ve $\mathrm{H} \gamma$ net gama doz hızı için elde edilen sonuçları göstermektedir. Örneklere ait kodlama için Tablo 2'deki kodlar kullanılmıștır. Doz hızları, bir numuneye ait iki örneğin ölçüm ortalamalarının ortalaması alınarak belirlenmiştir)

\begin{tabular}{|c|c|c|c|c|}
\hline $\begin{array}{l}\text { Numune } \\
\text { Kodu }\end{array}$ & $\underset{(\mathrm{mSv} / \mathrm{y} 1 \mathrm{l})}{\text { Htop }}$ & $\begin{array}{c}\mathrm{H} \alpha \\
(\mathrm{mSv} / \mathrm{y} 1 \mathrm{l})\end{array}$ & $\begin{array}{c}\mathrm{H} \beta \\
(\mathrm{mSv} / \mathrm{y} 1 \mathrm{l})\end{array}$ & $\begin{array}{c}\mathrm{H} \gamma \\
(\mathrm{mSv} / \mathrm{y} 1 \mathrm{l})\end{array}$ \\
\hline $\mathrm{C} 1$ & 1,84 & 0,13 & 1,43 & 0,28 \\
\hline $\mathrm{C} 2$ & 1,93 & 0,15 & 1,51 & 0,27 \\
\hline C3 & 1,86 & 0,19 & 1,43 & 0,24 \\
\hline $\mathrm{C} 4$ & 1,57 & 0,06 & 1,22 & 0,29 \\
\hline C5 & 1,49 & 0,09 & 1,15 & 0,25 \\
\hline N1 & 1,51 & 0,08 & 1,24 & 0,19 \\
\hline N2 & 1,56 & 0,11 & 1,21 & 0,25 \\
\hline N3 & 1,63 & 0,23 & 1,17 & 0,23 \\
\hline N4 & 1,65 & 0,12 & 1,29 & 0,25 \\
\hline N5 & 1,52 & 0,07 & 1,26 & 0,18 \\
\hline D1 & 2,14 & 0,21 & 1,72 & 0,20 \\
\hline D2 & 2,17 & 0,17 & 1,79 & 0,21 \\
\hline D3 & 2,13 & 0,18 & 1,75 & 0,19 \\
\hline D4 & 2,15 & 0,21 & 1,76 & 0,17 \\
\hline D5 & 1,85 & 0,16 & 1,47 & 0,22 \\
\hline $\mathrm{VC} 1$ & 1,75 & 0,17 & 1,42 & 0,17 \\
\hline $\mathrm{VC} 2$ & 1,86 & 0,24 & 1,42 & 0,20 \\
\hline VC3 & 1,65 & 0,05 & 1,43 & 0,18 \\
\hline VC4 & 1,67 & 0,18 & 1,31 & 0,17 \\
\hline VC5 & 1,59 & 0,15 & 1,27 & 0,17 \\
\hline VC6 & 1,74 & 0,09 & 1,51 & 0,14 \\
\hline I1 & 1,90 & 0,06 & 1,60 & 0,23 \\
\hline I2 & 1,89 & 0,04 & 1,62 & 0,23 \\
\hline I3 & 1,89 & 0,10 & 1,57 & 0,22 \\
\hline I4 & 1,95 & 0,14 & 1,57 & 0,24 \\
\hline I5 & 1,97 & 0,06 & 1,63 & 0,27 \\
\hline G1 & 1,70 & 0,18 & 1,31 & 0,22 \\
\hline G2 & 1,71 & 0,07 & 1,48 & 0,16 \\
\hline G3 & 1,76 & 0,29 & 1,30 & 0,17 \\
\hline G4 & 1,73 & 0,24 & 1,29 & 0,20 \\
\hline V1 & 1,57 & 0,12 & 1,31 & 0,14 \\
\hline V2 & 1,55 & 0,08 & 1,26 & 0,21 \\
\hline V3 & 1,46 & 0,22 & 1,08 & 0,16 \\
\hline V4 & 1,32 & 0,06 & 1,09 & 0,18 \\
\hline M1 & 1,80 & 0,10 & 1,49 & 0,21 \\
\hline M2 & 1,85 & 0,16 & 1,46 & 0,22 \\
\hline M3 & 1,83 & 0,13 & 1,47 & 0,23 \\
\hline M4 & 1,66 & 0,16 & 1,17 & 0,33 \\
\hline M5 & 1,65 & 0,09 & 1,32 & 0,24 \\
\hline M6 & 1,73 & 0,17 & 1,41 & 0,15 \\
\hline M7 & 1,78 & 0,15 & 1,49 & 0,14 \\
\hline M8 & 1,94 & 0,32 & 1,46 & 0,16 \\
\hline
\end{tabular}

Tablo 2' de verilen net doz hızı değerleri belirlenirken; dedektör gama filtresi ile kullanıldığında örneklere ait $\gamma$-radyasyonu kaynaklı doz hızının, alfa bloklayıcı kullanıldığında $\beta$ ve $\gamma$ kaynaklı doz hızının ve filtresiz ölçümlerde ise $\alpha, \beta$ ve $\gamma$ radyasyonlarının toplamı olan toplam doz hızının ölçüldüğü varsayılmıştır. Böylelikle, beta doz hızlarını belirleyebilmek için alfa bloklayıcı filtre ile alınan ölçümlerden, gama filtresi kullanılarak yapılan ölçümlerin çıkarılması yeterli olacaktır. Alfa doz hızları da benzer bir yaklaşımla (toplam doz hızı ölçümü sonuçlarından alfa bloklayıcı ile alınan ölçüm sonuçlarının çıkarılmasıyla) elde edilmiştir.

Numuneler üreticilerine göre karşılaştırıldığında, net toplam doz hızlarına ait ortalamalar Şekil 7'deki gibi sıralanmaktadır. En yüksek net toplam doz hızı ortalaması Degudent markasına ait ürünlerde, en düşük ortalama ise Vita markasına ait seramik tozlarında gözlenmiştir.

\section{Tartışma ve Sonuç}

Dental seramikler diş hekimliği uygulamalarında geniş bir kullanım alanına sahiptir. Dental seramik tozlarının doz hızı ölçümlerine ait ilk ulusal sonuçların sunulduğu bu çalışmada, Türkiye'deki dental malzeme sağlayan depolardan temin edilen 8 ticari markaya ait feldspatik yapıdaki 42 farklı dental seramik numunesi için 10'ar gramlık 2'şer örnek incelenmiştir. Örneklerin sahip olduğu net doz hızlarına ait ortalamalar; alfa doz hızı, beta doz hizı, gama doz hizı ve toplam doz hızı olarak belirlenmiştir. Isparta ili fon radyasyonu seviyesi Türkiye ve dünya ortalamalarının üzerindedir $(22,23)$. İncelenen dental seramik tozlarının tümünde, bu yüksek fon seviyesinin üzerinde ve kolaylıkla fark edilebilecek düzeyde ölçümler kayıt edilmiştir. Bununla birlikte, fon seviyesinin zamana bağlı değişimini kontrol edebilmek mümkün değildir. Herhangi bir örneğe ait ölçüm sürecinde fon düzeyinin (fon seviyesi olarak belirlenen ortalama değere göre) anlık olarak değişimi, GM dedektörünün filtresizken $6-10 \mathrm{keV}$ ve gama filtresi kullanıldığında $17 \mathrm{keV}$ ile $1,3 \mathrm{MeV}$ aralığındaki enerjilere sahip fotonları algılayabilmesi gibi etkenler, ölçüm sonuçlarının kesinliği üzerinde etkili olan faktörlerdendir. Çalışma limitleri dahilinde, incelenen numunelerdeki doğal kaynaklı net doz hızı ortalamalarının; $\alpha$ doz hızı bakımından

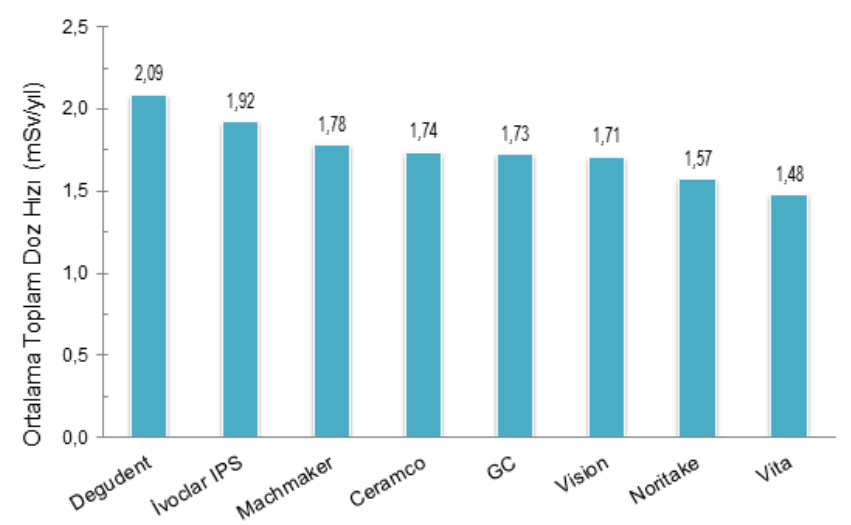

Şekil 7. Feldspatik dental seramik örnekleri için net toplam doz hızı ortalamalarının genel olarak marka bazında karşılaştırılması (Grafikteki toplam doz hızı düzeyleri Tablo 2'de verilen örneklere ait ortalamalardır). 
$0,04 \mathrm{mSv} / \mathrm{y}$ ıl ile $0,32 \mathrm{mSv} / \mathrm{y} ı 1$ aralığında değerler aldığ $1, \gamma$ doz hızı için $0,14 \mathrm{mSv} / \mathrm{y} 1 \mathrm{l}$ ile $0,33 \mathrm{mSv} / \mathrm{y} ı 1$ arasında değiştiği, $\beta$ doz hızı için 1,08 mSv/yıl ile 1,79 mSv/yıl aralığında olduğu ve toplam doz hızı için de 1,32 mSv/yıl ile 2,17 mSv/yıl seviyeleri arasında değiştiği bulunmuştur (Tablo 2). 84 örnek arasında, en düşük net toplam doz hızı 1,21 mS/yıl değeriyle V4 numunesine ait ilk örnekte ve en yüksek net toplam doz hız1 ise 2,26 mSv/y1l ile D2 numunesine ait ikinci örnekte gözlemlenmiştir. Numuneler Tablo 1'de verilen renk kodları açısından değerlendirildiğinde ise genel olarak, dentin ve opak uygulamaları için kullanılan A3 renk koduna sahip örneklerin A2 kodlu örneklere göre daha yüksek toplam doz hızı düzeyleri sergilediği söylenebilir (Tablo 2). Ayrıca, numunelerin tümüne ait genel ortalamaların; net $\alpha$ doz hızı için $0,14 \mathrm{mSv} / \mathrm{y} 1$, net $\gamma$ doz hızı için $0,21 \mathrm{mSv} / \mathrm{y} 1 \mathrm{l}$, net $\beta$ doz hızı için 1,41 mSv/yıl ve net toplam doz hızı için 1,76 mSv/ y1l düzeyinde olduğu tespit edilmiştir.

Numunelerdeki $\alpha, \beta$ ve $\gamma$ radyasyonlarına ait net doz hızlarının toplam doz hızına katkıları incelendiğinde, $\beta$-radyasyonunun payı, \%80 düzeyinde bir katkıyla ön plana çıkmaktadır. Bu durum, feldspatik dental seramiklerin yapısında yüksek miktarda Potasyum bulunmasıyla açıklanabilir. Potasyumun üç doğal izotopu mevcuttur $\left({ }^{39} \mathrm{~K},{ }^{40} \mathrm{~K}\right.$ ve $\left.{ }^{41} \mathrm{~K}\right)$. Bu izotoplardan sadece Potasyum-40 radyoaktiftir. Potasyum içeriğinin yaklaşık \%0,012'sini oluşturan ${ }^{40} \mathrm{~K}$ doğal bir $\beta$-yayınlayıcısıdır ve feldspatik seramiklerde yüksek $\beta$ doz hızı düzeylerinin

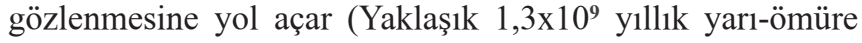
sahip 40K radyoizotopu, zamanının \%89'unda 1,32 MeV enerjili bir beta parçacığı $\left(\beta^{-}\right)$yayınlayarak Kalsiyum-40'a bozunur). Bu çalışmada elde edilen yüksek $\beta$ doz hızı düzeyleri literatür ile uyumludur. Veronese ve arkadaşlarının 2006 yılında yayınladığı bir çalışmada (12), dental materyallerdeki doğal radyonükleidlerden kaynaklanan beta doz hızları araştırılmış ve feldspatik porselen tozlarına ait doz hızı seviyesinin, fon radyasyonundan 10 kat daha yüksek olduğu belirtilmiştir. Isparta'daki fon radyasyonu seviyesi dünya ortalamasından daha yüksek olduğundan çalışmamızdaki beta doz hızına ait fon seviyesi $0,3 \mathrm{mSv} / \mathrm{y}$ ıl civarında bulunmuştur. 42 numunenin net beta doz hizlarına ait genel ortalamasının ise, bu düzeyin yaklaşık 5 katı civarında olduğu söylenebilir.

\section{Teşekkür}

$\mathrm{Bu}$ çalışma, Süleyman Demirel Üniversitesi Bilimsel Araştırma Projeleri Birimi Başkanlığı tarafından 3492-YL113 nolu proje kapsamında desteklenmiştir. Yazarlar, Süleyman Demirel Üniversitesi’ne teşekkür eder.

\section{Kaynaklar}

1. Sabol J, Weng, P-S. Introduction to Radiation Protection Dosimetry. Singapore: World Scientific Publishing; 1995: p. 300

2. Türkiye Atom Enerjisi Kurumu, Doğal Radyasyon Kaynakları. 2015: Erişim Tarihi: 26.03.2015. http://www. taek.gov.tr/belgeler-formlar/yayinlar/bilgi-dokumanlari

3. Kaya A. İyonize Radyasyonun Biyolojik Etkileri. Dicle Tip Dergisi 2002; 29(3): 65-75.
4. Sakaguchi RL, Powers JM. Craig's Restorative Dental Materials. 13th ed. Philadelphia: Elsevier; 2012: p. 254-259.

5. Shen JZ, Kosmac T. Advanced Ceramics for Dentistry. 1st ed. Waltham: Elsevier; 2014: p. 257-261.

6. McCabe JF, Walls AWG. Applied Dental Materials. 9th ed. Oxford: Blackwell Publishing; 2008: p. 89-90.

7. Schmalz G, Arenholt-Bindslev D. Biocompatibility of Dental Materials. Berlin: Springer-Verlag; 2009: p. 177-178.

8. Volpato CAM, Fredel MC, Philippi AG, Petter CO. Ceramic Materials and Color in Dentistry. Wunderlich W, ed. Ceramic Materials. Rijeka: Sciyo; 2010: 155-174.

9. Dietz C. United States Patent No 301. 1942, p.174.

10. Mack PJ. Uneasy Lies the Head that Wears the Crown? The Recent History of Radioactive Fluorescers in Dental Porcelain. Aust Dent J 1988; 33(5): 404-406.

11. Papastefanou C, Vitsentzos S, Garefis P. Uranium in Dental Porcelain Powders and Dose Induced in Oral Mucosa. Radiat Prot Dosimetry 1987; 19(1): 49-53.

12. Veronese I, Guzzi G, Giussani A, Cantone MC, Ripamonti D. Determination of Dose Rates from Natural Radionuclides in Dental Materials. J Environ Radioact 2006; 91(1-2): 1526.

13. US Nuclear Regulatory Commission. Systematic Radiological Assessment of Exemptions for Source and by Product Materials. (NUREG-1717) NUREG Report 2001. Sect.3: 24-25.

14. American National Standards Institute/American Dental Association. Specification No. 52. Uranium Content in Dental Porcelain and Porcelain Teeth. The J Am Dent Assoc 1979; 98(5): 755-757.

15. American National Standards Institute/American Dental Association. Specification No. 69 for Dental Ceramic. American Dental Association 1991. Chicago, Illinois.

16. International Organization for Standardization. Dental Ceramic. ISO FDIS 6872: Geneva. 2007.

17. European Commission. Laying Down Basic Safety Standards for Protection Against the Dangers Arising from Exposure to Ionising Radiation. EC 2012; p.242.

18. Resmi Gazete. Radyasyon Güvenliği Yönetmeliği 2000.

19. Krane KS. Nükleer Fizik Cilt 1. Birinci Bask1, Ankara: Palme Yayıncılık; 2001: p. 246-361.

20. Akkoyun S, Gama Işınlarının Yön Tayini. Ankara: Ankara Üniversitesi Fen Bilimleri Enstitüsü; 2003.

21. Thermo. RadEye B20 and B20-ER Multi-Purpose Survey Meters User's Manual. 2012.

22. Tozun F, Çine A, Kürkçüoğlu ME. Isparta İl Merkezine ait Gama Doz Hızı Düzeylerinin Yıllık Olarak İncelenmesi ve Haritalandırılması. ADIM Fizik Günleri-III, Süleyman Demirel Üniversitesi, Isparta, Türkiye, 17-18 Nisan 2014, Bildiri Özetleri Kitab1 108.

23. Kürkçüoğlu ME, Tozun F. Isparta İl Merkezindeki İş Yerlerinde Atmosferik Radon Ölçümleri. Süleyman Demirel Üniversitesi Fen Dergisi (e-dergi) 2015; 10(1): 62-74. 